\section{Levodopa withdrawal and the neuroleptic malignant syndrome}

Sir,

In the paper: 'Levodopa withdrawal syndrome identical to neuroleptic-malignant syndrome' (Gibb \& Griffith, 1986) the authors suggested that sudden withdrawal of dopaminergic drugs precipitated the development of neuroleptic-malignant syndrome (NMS) in their patient. However, it is difficult to reconcile the wide range of this patient's symptomatology with derangements of striatal and hypothalamic dopaminergic activity alone. We suggest that the factor operating in the patho-physiology of the NMS is based on hypothalamic endorphinergic dysregulation (Sandyk \& Iacono, 1986).

In that the hypothalamus: (1) controls autonomic functions, level of consciousness and motor activity (Clar, 1985; Ranson, 1939) and (2) is known to show early, selective degeneration in Parkinson's disease (Langston \& Forno, 1978) and (3) cerebrospinal fluid beta-endorphin levels are reported to be reduced in both aging and Parkinson's disease (PD) (Nappi et al., 1985), and (4) L-dopa administration also reduced hypothalamic beta-endorphin content (Locatelli et al., 1983) and (5) the activity of the hypothalamus is partially under endorphinergic control (Gambert $e t$ al., 1980), then withdrawal of Sinemet in this patient would conceivably result in excessive opioid activity in an already compromised hypothalamus. In addition, increase in the activity of the intrinsic opioids would lead to inhibition of the locus coeruleus (LC) noradrenergic activity, possibly resulting in alterations of cerebral blood flow (CBF) and level of consciousness (Strahlendorf et al., 1980; Demenet, 1976). Furthermore, intracerebro-ventricular administration of beta-endorphins has been reported to produce rigidity and catalepsy in rats (Sandyk, 1985), and a similar mechanism could have operated in the patient reported by Gibb and Griffith. Thus, a sudden excess of endorphinergic activity within the hypothalamus, analogous to that which is seen in septic shock rather than primary derangements of the dopaminergic system, may have been the central factor in the precipitation of NMS described in the patient reported. Given that this patient succumbed and mortality in NMS approaches $25 \%$ (Friedman et al., 1985) then in the future a therapeutic trial of naloxone based on our explanation may be warranted.

\section{R. Sandyk, Robert P. Iacono University of Arizona, Arizona Health Science Center, Tucson, Arizona 85724, USA.}

\section{References}

CLAR, H.E. (1985). Disturbances of the hypothalamic thermoregulation. Acta Neurochirurgica, 75, 106.

DEMENET, W.C., HOLMAN, R. \& GUILLEMINAULT, C. (1976). Neurochemical and neuropharmacological foundations of sleep disorders. Psychopharmacology Communications, 2, 77.

FRIEDMAN, J.H., FEINBERG, S.S. \& FELDMAN, R.G. (1985). A neuroleptic malignant like syndrome due to levodopa therapy withdrawal. Journal of the American Medical Association, 254, 2792.

GIBB, W.R.G. \& GRIFFITH, D.N.W. (1986). Levodopa withdrawal syndrome identical to neuroleptic malignant syndrome. Postgraduate Medical Journal, 62, 59.

GAMBERT, S.R., GARTHWAITE, T.L., PONTZER, C.H. \& HAGEN, T.C. (1980). Age-related changes in the central nervous system beta-endorphin and ACTH. Neuroendocrinology, 31, 252.

LANGSTON, J.W. \& FORNO, L.S. (1978). The hypothalamus in Parkinson's disease. Annals of Neurology, 3, 129.

LOCATELLI, V., PETRAGLIA, F., PENALVA, A. \& PANERAI, A.E. (1983). Effect of dopaminergic drugs on hypothalamic and pituitary immunoreactive beta-endorphin concentration in the rat. Life Sciences, 33, 1711.

NAPPI, G., PETRAGLIA, F., MARTIGNONI, E. \& FACCHINETTI, F. (1985). Beta-endorphin cerebrospinal fluid decrease in untreated parkinson patients. Neurology, 35, 1371.

RANSON, S.W. (1939). Somnolence causes of hypothalamic lesions in the monkey. Archives of Neurology and Psychiatry, 41, 1.

SANDYK, R. (1985). The endogenous opioid system in neurological disorders of the basal-ganglia. Life Sciences, 37, 1655.

SANDYK, R. \& IACONO, P.R. (1986). Neuroleptic-malignant syndrome. Journal of the American Medical Association (in press).

STRAHLENDORF, H.K., STRAHLENDORF, J.C. \& BARNES, C.D. (1980). Endorphin-mediated inhibition of locus coeruleus. Brain Research, 191, 284.

This letter has been shown to Dr Gibb who replies:-

Sir,

The possibility that derangement of beta-endorphin levels in the hypothalamus may be responsible for the neuroleptic-malignant syndrome (NMS) is interesting, if improbable. But the suggestions made are constructive. I am not aware however that hypothalamic beta-endorphins have been shown to mediate hyperthermia. As suggested by the authors a trial of naloxone is warranted, but the success of naloxone would not confirm their hypothesis that endorphins play a primary role in the genesis of NMS. The problem about NMS is that an hypothesis implicating the hypothalamus is entirely speculative. Contrary to the

(C) The Fellowship of Postgraduate Medicine, 1986 